\title{
HEADSPACE ANALYSIS OF AROMA COMPOUNDS USING POROUS ADSORBENTS
}

\author{
N.M. Emanuel Institute of Biochemical Physics, Russian Academy of Sciences, \\ 4 Kosygin str., M oscow, 119334 Russia; tmish@rambler.ru
}

Received: February 10, 2010 / Revised: April 21, 2010 / Accepted: September 06, 2010

(C) Misharina T., 2011

\begin{abstract}
A novel procedure is developed for the quantitative determination of volatile compounds in the vapour phase over samples. Substances were extracted and preconcentrated from the headspace on porous polymer adsorbents under the conditions of thermodynamic equilibrium, followed by back extraction from the adsorbent using organic solvents. The final monitoring was performed by capillary gas chromatography with an internal standard. The influence of adsorption time and the concentration of substances in an aqueous solution on the degree of extraction were also studied; linear correlations between the quantities of substances in the gas and aqueous phases were found. The method was used for the determination of volatile substances in the gas phase over liquid and solid matrixes of different composition.
\end{abstract}

Keywords: adsorbent, headspace analysis, quantitative determination, volatile compounds, composition.

\section{Introduction}

The composition and concentration of volatile organic substances (odorants) in the gas phase over foods determine their aroma. Odorants are released from the bulk of food matrix and transfer into the gas phase according to their volatility. The odorants release is affected by their structure, by the presence and type of functional groups, by the concentration of the odorants in initial material, as well as by the composition and physicochemical state of the food matrix. Moreover, in the odorant release, an important input is contributed to their interactions with food biopolymers and lipids [1, 2]. Ordinarily, the composition of volatile substances in food has a rather complicated profile, e.g., the number of substances can reach several hundred, while the total concentration of individual species does not exceed $0.01 \%$, and the range of concentrations for the volatile substances can be several orders of magnitude [3]. The complexity of such objects substantially restricts the line of acceptable analytical methods for sample preparation and final detection of volatile substances.

To determine volatile substances in the vapour phase over the product, static or dynamic methods of analysis are used $[4,5]$. The dynamic technique includes the extraction of volatile odorants with a flow of an inert gas followed by their trapping by porous adsorbents. Then, the substances are thermally desorbed into the initial section of a GC column or eluted with organic solvents. Since the process does not appear to be in equilibrium, there is no chance to estimate the real ratio of the odorants forming the aroma of the product [4-6].

In the static procedure, the composition of volatile substances in the gas phase is determined in a closed container under the condition of thermodynamic equilibrium. Such an approach allows to analyze true aroma of a product. In the most common case, 1-10 ml of vapors are injected into a GC column; the composition is determined by the areas of chromatographic peaks then. However, the method is characterized by several significant restrictions including low sensitivity and reproducibility of determination, especially in the case of capillary gas chromatography, as this method detects only substances present in concentrations sufficient for the detector. Meanwhile, many key substances which are responsible for the products' aroma are present in the amounts that are too low for registration without additional preconcentration. Moreover, the method does not allow the use of internal standards and requires calibration of all procedures [5-8]. Recently, a method of solid phase micro extraction has been used, in which volatile substances from the headspace are collected by special tools on a layer of a liquid or a solid polymer (or mixtures of polymers), then the concentrate is thermally desorbed directly into the injection unit of a chromatograph and analyzed [7-10]. The technique also confines the utilization of an internal standard, which makes the obtaining of reliable quantitative results rather 
difficult. Thermal desorption from a polymer matrix requires a certain amount of time (a minute approximately), which leads to the drop in the quality of the chromatographic separation itself [11]. The comparison of some sorption methods for the isolation of volatile substances has revealed an essential spread among the data on the qualitative and quantitative composition of odorants in the same specimen of cheese [12], cured ham [13] and whisky [14]. As a rule, the method of solid phase extraction has given undersized results.

Meanwhile, the porous and hydrophobic polymer adsorbents with highly developed surfaces possess high sorption activity and capacity in relation to a wide spectrum of organic substances, including the volatile ones. The retention of substances by this type of adsorbents is determined by the physical adsorption on the surface and in the pores and capillaries due to van der Waals and electrostatic forces. The binding is rather reversible, and the substances retained can be released easily by thermal desorption or back extraction with a solvent $[4-7,15]$. These polymers are usually used in cartridges for the dynamic vapor analysis. The author used the adsorbents in the mode of static headspace analysis.
Herein, the author reports a novel version of the solid phase extraction of volatile substances from the headspace over samples and its application to the analysis of model systems and real foods.

\section{Experimental}

\subsection{Model Mixtures of Odorants}

Two model mixtures of odorants were used, prepared by dissolving individual substances $20-200 \mu \mathrm{l}$ each in $2 \mathrm{ml}$ of ethanol (Mixture 1) and essential oils of oregano and nutmeg to which individual odorants of carvone, camphor, caryophyllene, and eugenol were added (Mixture 2). According to the GC data, all materials contained not less than $98 \%$ of the main component. To control the qualitative composition of the mixtures, $10 \mu \mathrm{l}$ of each mixture were diluted in $100 \mu \mathrm{l}$ of ethanol, and then $1 \mu \mathrm{l}$ of a $10 \% n$-dodecane solution was added as an internal standard. The resulting mixture was analyzed by capillary gas chromatography. The composition of the mixtures, the concentration of the odorants (relative to the $n$-dodecane), and their basic parameters are presented in the Table.

Table

\section{Characteristics of odorants and their concentrations} in model mixtures (relatively to $\boldsymbol{n}$-dodecane)

\begin{tabular}{|c|c|c|c|c|c|}
\hline Compound & $\begin{array}{l}\text { Mixture } \\
\text { no }\end{array}$ & $\begin{array}{l}\text { Relative content in } 10 \mu \mathrm{l} \text { of } \\
\text { a model mixture }\end{array}$ & $\begin{array}{l}\text { MW, } \\
\mathrm{g} / \mathrm{mol}\end{array}$ & $\begin{array}{c}\text { Hydrobocity } \\
\left(\log P_{\text {octanol/water }}\right)[16]\end{array}$ & $\begin{array}{l}\text { Retention index } \\
\text { on DB-1 }\end{array}$ \\
\hline \multicolumn{6}{|l|}{ Esters } \\
\hline Ethyl butyrate & 1 & 210 & 116 & 1.70 & 784 \\
\hline Amyl acetate & 1 & 216 & 130 & 2.15 & 880 \\
\hline Hexyl acetate & 1 & 236 & 144 & 2.83 & 996 \\
\hline Geranyl acetate & 1 & 97 & 196 & 4.04 & 1364 \\
\hline \multicolumn{6}{|c|}{ Terpene hydrocarbons } \\
\hline$\alpha$-Pinene & 2 & 569 & 136 & 4.16 & 932 \\
\hline Limonene & 1 & 490 & 136 & 4.38 & 1025 \\
\hline$\gamma$-Terpinene & 2 & 310 & 136 & 4.36 & 1050 \\
\hline Caryophyllene & 2 & 516 & 204 & - & 1420 \\
\hline \multicolumn{6}{|c|}{ Alcohols and aldehyde } \\
\hline 2-Hexenal & 1 & 240 & 98 & 1.58 & 832 \\
\hline Hexanol & 1 & 250 & 102 & 2.03 & 852 \\
\hline Heptanol & 1 & 254 & 116 & 2.45 & 954 \\
\hline Octanol & 1 & 210 & 130 & - & 1055 \\
\hline Linalool & 1 & 655 & 154 & 3.50 & 1085 \\
\hline \multicolumn{6}{|c|}{ Ketones and phenols } \\
\hline Camphor & 2 & 151 & 152 & 2.74 & 1125 \\
\hline Carvone & 2 & 610 & 150 & 2.75 & 1218 \\
\hline Thymol & 2 & 783 & 150 & 3.30 & 1278 \\
\hline Eugenol & 2 & 945 & 164 & 2.99 & 1330 \\
\hline Myristicin & 2 & 120 & 192 & - & 1492 \\
\hline
\end{tabular}




\subsection{Porous Adsorbents}

We used three porous adsorbents (Supelko, USA): Tenax GC (40-60 mesh), representing the polymer of $n$-2,6-diphenylene oxide with a specific surface area of $18.6 \mathrm{~m}^{2} / \mathrm{g}$ and average pore size of $72 \mathrm{~nm}$; Porapack R (60-80 mesh) was based on poly- $N$-vinylpyrrolidone and had specific surface area of $550-570 \mathrm{~m}^{2} / \mathrm{g}$. Chromosorb 105 (60- 80 mesh) was a polyaromatic polymer with a specific surface area of $600-700 \mathrm{~m}^{2} / \mathrm{g}$ and average pore size of $50 \mathrm{~nm}$ [5]. Prior to use, all adsorbents were washed with ethanol, ether, and acetone and kept in a flow of helium for $24 \mathrm{~h}$ at $523 \mathrm{~K}$ in a thermostat.

\subsection{Extraction of Volatile Substances}

To extract volatile substances from the gas phase, a $0.5 \mathrm{ml}$ Erlenmeyer flask was sequentially charged with $10 \mathrm{ml}$ of distilled water, $10 \mu \mathrm{l}$ of model mixture 1 or 2 , then closed with a glass stopper and kept at ambient temperature (295- $226 \mathrm{~K}$ ) for $2 \mathrm{~h}$. A chemical glass with a diameter of $1.8 \mathrm{~mm}$ and height of $20 \mathrm{~mm}$ was charged with $100 \mathrm{mg}$ of one of the porous adsorbents specified and positioned on the bottom of the flask with a model solution. Then, the flask was corked up again and kept for $3 \mathrm{~h}$ to compare the effectiveness of the adsorbents and evaluate the odorant concentration in aqueous solutions in relation to the degree of extraction. Kinetic curves were built using a set of nine samples (10 ml each); the exposure time for the polymer in the gas phase over aqueous solutions was $30 \mathrm{~min}, 1,2,3,4,5,18,24$, and 48 hours. Then the glass was extracted from the flask, and the adsorbent was transferred into a glass test tube. Diethyl ether $(1 \mathrm{ml})$ and $5 \mu \mathrm{l}$ of $1 \%$ ethanolic solution of $n$-dodecane were added to the polymer. The mixture was shaken for $10 \mathrm{~min}$ followed by the decantation of the liquid into a clean test tube. Extraction was repeated without the addition of $n$-dodecane. The extracts were combined and, if necessary, evaporated using a $35-\mathrm{cm}$ long Vigreux column at $313 \mathrm{~K}$ to get the residual volume of $0.2-0.4 \mathrm{ml}$. A special check was performed, which showed that the procedure guaranteed the quantitative extraction of the odorants. Each experiment was repeated 3-5 times.

\subsection{Gas Chromatographic Analysis}

The extracts were analyzed on an HP 5730 chromatograph (Hewlett Packard, USA) equipped with a fused silica capillary column DB-1 $(50 \mathrm{~m} \times 0.32 \mathrm{~mm}$, immobile phase width $d_{f}=0.25 \mu \mathrm{m}$ ) operated at the temperature from 333 to $523 \mathrm{~K}$ with the gradient rate $8 \mathrm{~K} / \mathrm{min}$. The rate of carrier gas helium was $1 \mathrm{ml} / \mathrm{min}$, the temperature of the injector unit and flame-ionization detector was $523 \mathrm{~K}$. The volume of the sample was $25 \mu \mathrm{l}$. The chromatograms were registered by the Ecochrom (State Registration no. 16616-97, Russia) system for the collection and processing of chromatography data. The relative concentration of the components in the initial model solutions and samples was calculated from the comparison of peaks referring to the components and the internal standard by simple adjustment, and expressed in units, equivalent to the number of $\mu \mathrm{g}$ of $n$-dodecane. The efficiency of extraction (\%) was determined as the ratio of the odorant quantity found in the gas phase to the quantity introduced into the aqueous solution. The procedure made the determination of the sensitivity coefficients of the detector to compounds of various structures unnecessary, therefore these coefficients were cancelled in the calculation. The processing and averaging of the data obtained were performed using the ANOVA software at the value $p<0.05$. The plotting, construction of linear correlations and their processing were realized using the Origin 7.5 software.

\section{Results and Discussion}

The traditional static analysis of the gas phase is based on the equilibrium distribution of the substances between liquid or solid and gas phases in a closed space and the determination of the concentration of volatile substances in vapors. All general methods for the determination of volatile substances in vapors, their theoretical and practical aspects, benefits, and drawbacks are considered in detail in the reviews $[4,5]$. The actual version included the adsorption of volatile substances from the gas phase by porous adsorbents under batch conditions; the quantity of the adsorbent could be changed to fit the desired task under consideration. Upon exposure, the concentration of species in vapors reduced gradually, and new portions transferred from aqueous into the gas phase according to their distribution coefficients. Finally, the entire process resulted in the preconcentration of volatile substances on a porous adsorbent, which allowed for the improvement of the accuracy, reproducibility and effectiveness of the parameters of the following GC determination of the contents of the odorants, released from the products to the gas phase over them. The retained substances were eluted by diethyl ether in the presence of an internal standard; therefore, the sample could be further preconcentrated, analyzed by a number of GC and GC-MS methods under various conditions and processed quantitatively. To summarize, the major advantages of the technique reported were represented by its simplicity, no need for special equipment, and the possibility of using an internal standard to quantify the entire determination.

The study of odorant adsorption from vapors over their aqueous solution revealed a correlation between the efficiency of extraction and the structure of the analyte and the adsorbent nature. Fig. 1 presents the degree of 
extraction of a model mixture of odorants relating to various classes of organic compounds from vapors over their aqueous solution using three porous adsorbents upon exposure for $3 \mathrm{~h}$. Porapack $\mathrm{R}$ and Chromosorb 105 appeared to have an identical sorption activity, while the activity of Tenax appeared to be almost two times lower. Since the concentration of volatile species over all adsorbents was identical, the effect apparently corresponded to the lower affinity of Tenax toward nonpolar odorants in comparison to Porapack $\mathrm{R}$ and Chromosorb. The lower sorption activity of Tenax filled traps was observed before under the conditions of dynamic headspace analysis [7].

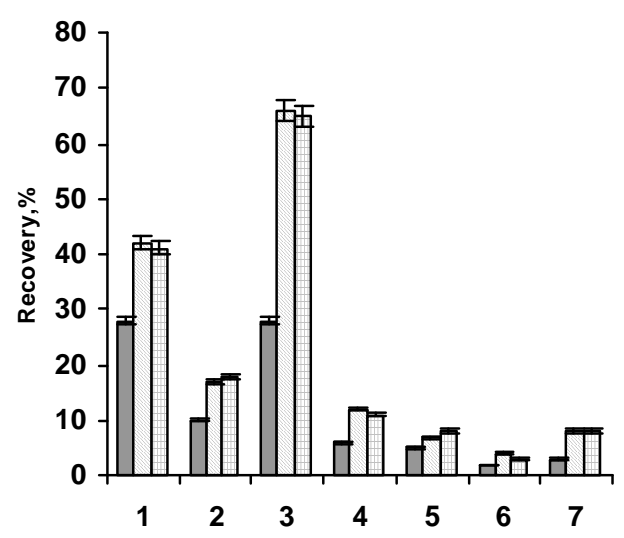

$\square$ Tenax $\square$ Porapak R $\square$ Chromosorb 105

Fig. 1. Recovery of odorants from the gas phase over an aqueous solution (three porous adsorbents, $3 \mathrm{~h}$ ): hexyl acetate (1); geranyl acetate (2); limonene (3); caryophyllene (4); heptanol (5); eugenol (6) and camphor (7)

Lower esters (see the Table) demonstrated a similar degree of extraction, which was $42-56 \%$ for Porapack R; geranyl acetate was extracted to $17 \%$ only. After exposure over Porapack R and Chromosorb for $3 \mathrm{~h}$, only $48-66 \%$ of monoterpene hydrocarbons (pinene, limonene and terpinene) and $12-13 \%$ of sesquiterepene caryophyllene were isolated. All adsorbents showed a low extraction degree for polar substances: alcohols, ketones, aldehyde, and phenols that were likely determined by the lower volatility of the polar odorants from aqueous solutions. Thus, if we compare the adsorption properties for the three adsorbents, Tenax demonstrated the lowest activity and was excluded from further investigation. Chromosorb 105 and Porapack R showed similar adsorption properties (Fig. 1); to study in detail the behavior of odorants under the conditions of static headspace analysis, Porapack R was chosen.

Fig. 2 presents relative kinetic curves (those adjusted to the initial concentration of each odorant in the model solution), which illustrate the relation of exposure time to the extraction degree of components by Porapack R. As can be seen, the longer the exposure time, the bigger the quantity of substances trapped; however, the specific rate of accumulation depended on the structure of the substances and their hydrophobic properties. Generally, the extraction of components from the gas phase over their aqueous solution (or that of other food species) appeared to be a two-step process: the transition of odorants from water into the gas phase followed their adsorption on a polymer matrix. The overall process is called extraction, it depends on two sets of distribution coefficients of the odorants: between the gas and aqueous phases and between the gas phase and the adsorbent surface. The distribution coefficients reflect the sum of the interactions between the odorants and the matrix, and the affinity of the volatile species to the adsorbents. The time of settlement of the sorption equilibrium is determined by the hydrophobic properties, molecular weight, and diffusion parameters of odorants in the medium $[17,18]$. The equilibrium retention by an adsorbent is a quick process, since diffusion in gas proceeds much faster than in liquids. Under such conditions, the rate-limiting step is the transition of odorants from liquid into the gas phase. Therefore, the obtained relations of the degree of extraction of substances to the exposure time (kinetic curves) could be used for calculation of the kinetic parameters for the release of odorants from aqueous solutions or another matrix. The rate of the evolution is determined by the slope of the kinetic curves in their linear segments. Finally, the rate constant of transfer is calculated based on the rate of release and the initial concentration of the substances in the sample. These parameters are crucially important for the evaluation of stability of product aroma and the identification of components responsible for the formation of the entire aroma.

The maximum degree of extraction was observed for nonpolar esters with low molecular weights: ethyl butyrate, amyl and hexyl acetates as well as for hydrocarbons pinene, limonene, and terpinene (Figs. 2a and $b$ ). In three hours, Porapack $\mathrm{R}$ extracted around one half of the substances from an aqueous solution; a fairly good quality extraction was achieved in 18-24 h. The less volatile nonpolar substances of the same class, geranyl acetate and caryophyllene, were $46-47 \%$ extracted after exposure for $48 \mathrm{~h}$. In the series of esters, the growth of molecular weight was accompanied by the enhancement of hydrophobic properties (see the Table); however, volatility in this series reduced, which resulted in the decrease of the extraction degree of the odorants. Within the series of monoterpene hydrocarbons with equal molecular weights, hydrophobicity increased in the following order: pinene $<$ terpinene $<$ limonene. The same order was found to determine their degree of extraction from aqueous solutions (Fig. 2b). Analogous behavior was registered for alcohols as well: hexanol, heptanol, and octanol. Despite the growth of molecular weight, the enhanced hydrophobic properties led to a higher degree of 
extraction; however, the absolute value was only 5-7\% in $3 \mathrm{~h}$, and did not exceed 30-39\% in $48 \mathrm{~h}$ (Fig. 2c). The determined degree of extraction for linalool appeared lower than that for octanol, its behavior copied heptanol's behavior. 2-Hexenal tended to be extracted easier than alcohols, in $20 \mathrm{~h}$ more than one half of the substance was transferred from aqueous solution into the gas phase (Fig. 2c). Fig. $2 d$ presents kinetic curves for carvone, thymol, and myristicin. The substitution of the hydroxyl group in myristicin by nonpolar groups increased its extraction degree from aqueous solution fivefold in comparison to thymol. The kinetics and extraction degree for camphor and eugenol had the same values as those for carvone and thymol, respectively. The assumption that the poor extraction of alcohols was determined by their low concentration in the gas phase over the aqueous solution and did not indicate the low true affinity of the adsorbent to this class of organics was proved by the data obtained for the same mixture in an empty flask with no solvent.
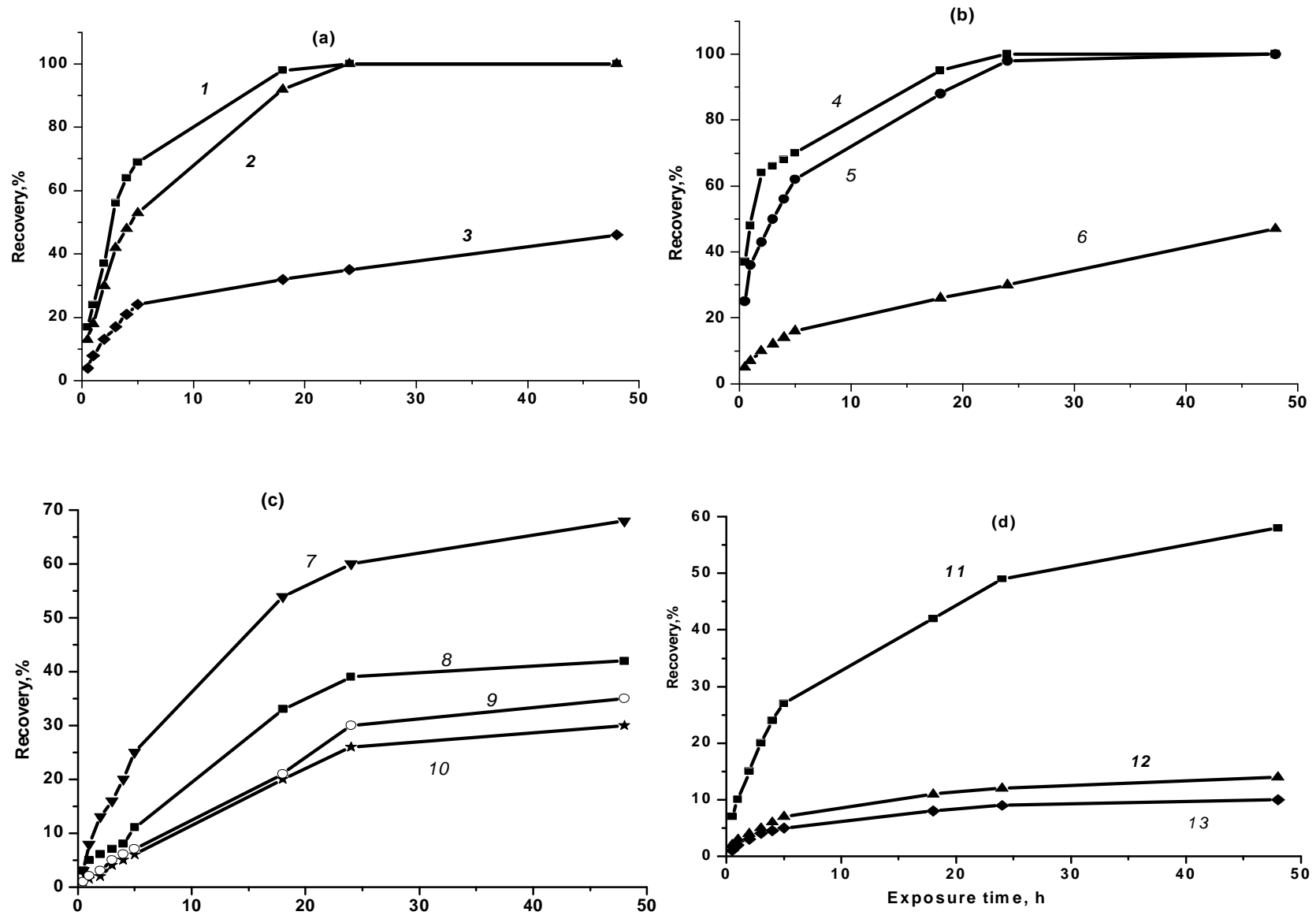

Fig. 2. Time dependence of extraction degree by Porapack R from vapors over an aqueous solution: ethyl butyrate (1); hexyl acetate (2); geranyl acetate (3); limonene (4); pinene (5); caryophyllene (6); 2-hexenal (7); octanol (8); linalool (9); hexanol (10); myristicin (11); carvone, camphor (12) and thymol, eugenol (13)

Fig. 3 presents a comparison of the degrees of extraction for equal quantities of odorant mixtures from an aqueous solution and with no solvent in $3 \mathrm{~h}$. The extraction of alcohols and aldehydes by Porapack R from vapors over solvent-free mixtures exceeded the value over an aqueous solution by $10-15$ times and, for nonpolar odorants, by $1.5-$ 2 times (Fig. 3). Apparently, the difference reflected the interaction of odorants with water, resulting in their lower concentration in the gas phase. Hence, the interaction of nonpolar compounds, hydrocarbons and esters, with water appeared much weaker in contrast to alcohols and aldehydes. The difference between the odorant composition over an aqueous solution and the same solution in the presence of some food polymer, e.g. protein or polysaccharide, or emulsion, provided the grounds for evaluation of the interaction of the odorant with food polymers and determination of distribution coefficients between various phases [2, 19-24]. 


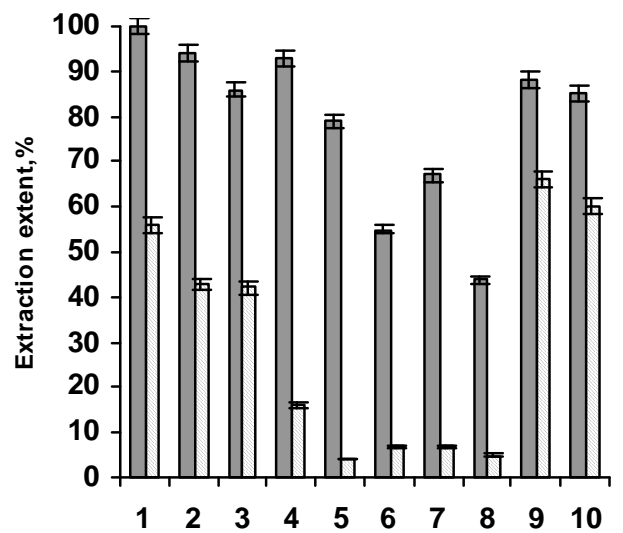

$\square$ Solvent-free odorants mixture

$\square$ Aqueous solution of odorants mixture

Fig. 3. Comparison of extraction extent of odorants by Porapack $\mathrm{R}$ from vapors over a solvent-free mixture and its aqueous solution (3 h): ethyl butyrate (1); amyl acetate (2); hexyl acetate (3); 2-hexenal (4); hexanol (5); heptanol (6); octanol (7); linalool (8) and limonene (9)
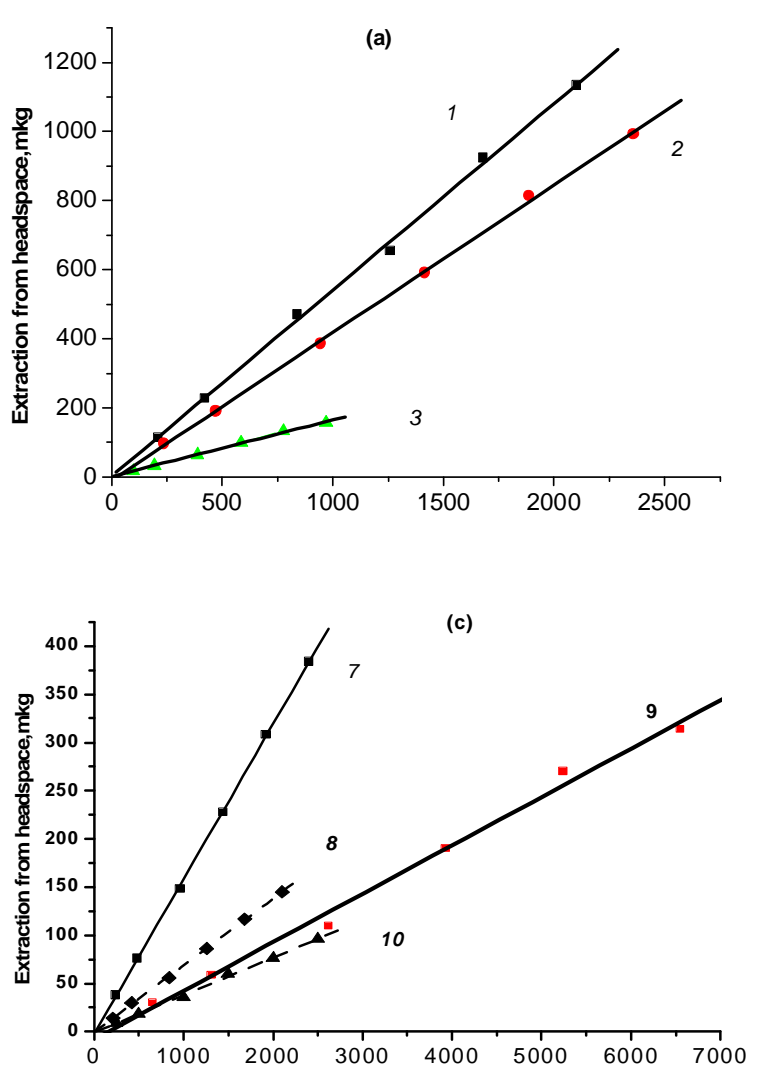

Fig. 4a illustrates the relation of the odorant quantity introduced into the initial aqueous solution to that trapped by Porapack $\mathrm{R}$ from the gas phase over $3 \mathrm{~h}$. The obtained relations were found to be linear in the concentration range checked (from 90 to $8000 \mu \mathrm{g}$ ). The linear behavior of the relations revealed the constant character of the degree of extraction for each odorant; it was independent of concentration. Therefore, both processes of the transition of odorants from the aqueous phase into vapors and the following accumulation on a porous adsorbent were clearly thermodynamically equilibrium. Such behavior allowed the use of the method proposed in flavor chemistry; for instance, to determine the kinetic and thermodynamic parameters of the release of odorants, to reveal substances that specify the aroma of food, and estimate the interaction of volatile organics with polymer components of food matrixes, etc. In combination with the method of phase ratios, one can simply and reliably measure the distribution constants of odorants between the gas phase and the food substance or another object [24-27]. As a practical example, Fig. 5 presents the estimated time dependence of odorant release from some liquid solvents and dry supporters for the
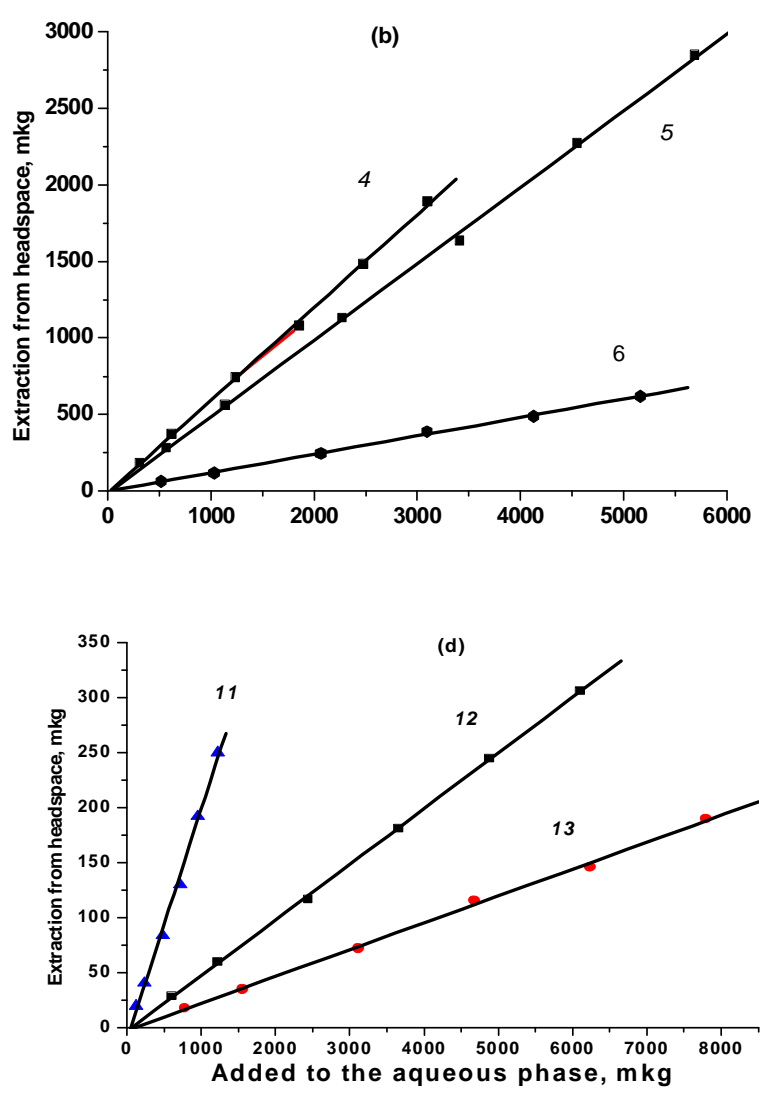

Fig. 4. Effect of odorant concentration in the aqueous phase on their content the gas phase: ethyl butyrate (1); hexyl acetate (2); geranyl acetate (3); limonene (4); pinene (5); caryophyllene (6); 2-hexenal(7); octanol (8); linalool (9); hexanol (10); myristicine (11); carvone, camphor (12) and thymol, eugenol (13) 
selection of a matrix that would provide the desirable presence of essential oil components in vapors. The amount of the essential oil mixture and concentration of each individual component, the volumes of the gas phases were kept similar or identical, and all other conditions were kept equal. As expected, the nature of solvent and matrix substantially influenced the odorant composition in vapors. Thus, hydrocarbons vaporized easily from propylene glycol, less easily from triacetin and maltodextrin, and were retained very well by vegetable oil. Alcohols and phenols were found to leave maltodextrin most easily, in contrast to the liquid matrixes tested. The retention of phenols by triacetin and starch was close to each other. The ratio of substances in the initial mixture of essential oils due to their transfer to the gas phase was reproduced best in the case of maltodextrin matrix used dry. This material was chosen to maintain the predetermined concentration of volatile species in chambers for tests on laboratory animals.

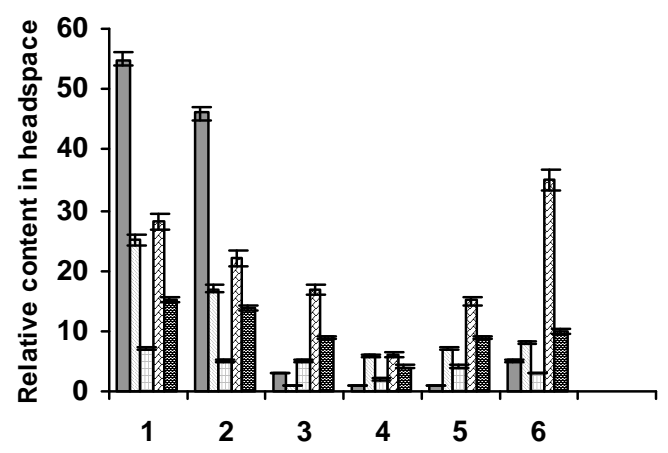

$$
\begin{aligned}
& \square \text { Propylene glycol } \square \text { Triacetin } \\
& \square \text { Vegetable oil } \quad \text { Maltodextrin } \\
& \text { Starch }
\end{aligned}
$$

Fig. 5. Concentration of odorants in the gas phase over solutions and dry disperse samples containing equal quantities of essential

oils (24 h, ambient temperature): pinene (1); limonene (2);

linalool (3); thymol (4); carvacrol (5) and eugenol (6)

\section{Conclusions}

New version of the quantitative determination of volatile organics in the gas phase over samples using porous adsorbents was developed. The method proposed is simple and allows for the application of internal standards and the analysis of complex mixtures by chromatography and other techniques. The quantities of substances in the vapor and aqueous solution were found to correlate linearly, which revealed the thermodynamic equilibrium behavior of extraction and preconcentration on porous adsorbents. Therefore, the extraction degree of odorants was independent of their concentration in the initial solution. Extended exposure time was shown to favor an increase in the degree of extraction, while the specific rate of accumulation was affected by the structure of the substance, its hydrophobic properties, and the nature of the matrix. The method was proved to be applicable to various tasks in flavor chemistry.

\section{References}

[1] Wilson C. and Brown W.: J. Sens. Stud., 1997, 21, 69.

[2] Seurve A., Diaz M. and Voilley A.: J. Agric. Food Chem., 2000, 48, 4296.

[3] Golovnya R. and Misharina T.: Zh. Anal. Khim., 1981, 36, 1390.

[4] Ettre L.: [in:] Rouseff R. and Cadwallader K. (Eds.) Headspace Analysis of Food and Flavours: Theory and Practice. Academic Plenum, New York 2001.

[5] Nongonierma A., Cayot P., Le Quere J. et al.: Food Rev. Int., 2006, 22, 51.

[6] Zhu J. and Chai X.-C.: Curr. Anal. Chem., 2005, 1, 79.

[7] Flamini G.: Curr. Anal. Chem., 2007, 3, 149.

[8] Angerosa F., Servili M., Selvaggini R. et al.: J. Chromatogr. A, 2004, 1054, 17.

[9] Arthur C. and Pawliszyn J.: Anal. Chem., 1990, 62, 2145.

[10] Baltussen E., Sandra P., David F. and Cramers C.: J. Microcolumn Sep., 1999, 11, 737.

[11] Vichi S., Castellote A., Pizzale L. et al.: J. Chromatogr. A, 2003, 983, 19.

[12] Bellesia F., Pinetti U., Rinaldi R. et al.: Food Chem., 2003, 83, 55 .

[13] Ruiz J., Cava R., Ventanas J. and Jensen M.: J. Agric. Food Chem., 1998, 46, 4688.

[14] Demyttenaere M., Sanchez Martinez J., Verhe R. et al.: J. Chromatogr. A, 2003, 985, 221.

[15] Tienpont B., David F., Bicchi C. and Sandra P.: J. Microcolumn Sep., 2000, 12, 577.

[16] Griffit S., Wyllie S. and Markham J.: J. Chromatogr. A, 1999, 894, 221.

[17] Zhu P.-L., Liu C.-L. and Liu M.-C.: J. Chromatogr. A, 2003, 988, 25.

[18] Zhang Z. and Pawliszyn J.: J. Anal. Chem., 1993, 65, 1843.

[19] Engels W., Dekker R., Jong C. et al.: Int. Dairy J., 1997, 7, 255.

[20] Guitard R., Puigdemont A. and Arboix A.: J. Chromatogr., 1989, 491, 271.

[21] Seure A., Philippe E., Rochard S. and Voilley A.: Food Res. Int., 2007, 40, 480.

[22] Guichard E.: Food Rev. Int., 2002, 18, 49.

[23] Jouquand C., Ducruet V. and Giampaoli P.: Food Chem., 2004, 85, 467.

[24] Savary G., Guichard E., Doublier J.-L. and Cayot N.: Food Res. Int., 2006, 39, 372.

[25] Ettre L., Welter C. and Kolb B.: Chromatographia, 1993, 35, 73.

[26] Athes V., Pena Y., Lillo M. et al.: J. Agric. Food Chem., 2004, 52, 2021.

[27] Bylaite E., Ilgunaite Z., Meyer A. and Alder-Nissen M.: ibid, 3542.

\section{АНАЛІЗ ПАРОВОЇ ФАЗИ АРОМАТИЧНИХ СПОЛУК З ВИКОРИСТАННЯМ ПОРИСТИХ АДСОРБЕНТІВ}

\footnotetext{
Анотація. Розроблена нова методика кількісного визначення летких сполук у паровій фазі над зразками. Речовини були екстраговані і попередньо сконцентровані з парової фази полі-
} 
мерних пористих адсорбентів за умов термодинамічної рівноваги, з подальшим їх екстрагуванням з адсорбентів за допомогою органічних розчинників. Заличковий контроль був проведений з використанням капілярної газової хроматографії та застосуванням внутрішнього стандарту. Вивчено вплив тривалості адсорбиї та кониентрачії речовин у водному розчині на ступінь вилучення $і$ знайдено лінійні кореляції між кількістю речовини в газовій та водній фазах. Запропоновано використовувати такий метод для визначення летких речовин в газовій фазі над рідкими та твердими матричями різного складу.

Ключові слова: адсорбент, аналіз парової фази, кількісне визначення, леткі сполуки, композиція. 